\title{
SINTESIS DAN KARAKTERISASI SILIKA GEL DARI LIMBAH KACA SERTA APLIKASINYA PADA KROMATOGRAFI KOLOM
}

\author{
Verry Andre Fabiani ${ }^{1}$, Nelly Wahyuni ${ }^{2}$, Ridho Brilliantoro ${ }^{2}$, Mellisa Nurul Safitri $^{2}$ \\ 1 Jurusan Kimia, Fakultas Teknik, Universitas Bangka Belitung \\ 2 Jurusan Kimia, Fakultas Matematika dan Ilmu Pengetahuan Alam, Universitas Tanjungpura
}

*Corresponding author: verry-andre@ubb.ac.id

\begin{tabular}{l}
\hline ARTICLE INFO \\
Article history: \\
Received 21 May \\
2018 \\
Accepted 28 May \\
2018 \\
Available online \\
26 June 2018 \\
\\
Keywords: \\
Column \\
chromatography \\
Glass waste \\
Hydrochloride acid \\
Silica gel
\end{tabular}

\begin{abstract}
Silica gel synthesis from glass waste have been carried out with activation and purification method by using hydrochloride acid. Hydrochloride acid were varied $8 \mathrm{~N}, 10 \mathrm{~N}$, and $12 \mathrm{~N}$ to observe optimum concentration in purification of silica gel and component separation in chromatography column. Gravimetric analysis result showed $12 \mathrm{~N}$ hydrochloride acid produce $\sim 100 \%$ silica. XRD and FTIR analysis revealed that synthetic gel silica was amorphous where its IR absorption bands were at $3426 \mathrm{~cm}^{-1}, 1620 \mathrm{~cm}^{-1}, 1080$ $\mathrm{cm}^{-1}, 772 \mathrm{~cm}^{-1}$ and $478 \mathrm{~cm}^{-1}$. The absorption bands agreed to standard gel silica and spectrum. The most effective $\mathrm{HCl}$ in gel silica synthesis was $12 \mathrm{~N}$, caused by its ability to separate color component in a column. The synthetic silica that can be applied as stationary phase in column chromatography.
\end{abstract}

(C) 2018 IJoPAC. All rights reserved

\section{Pendahuluan}

Silika gel merupakan suatu bentuk dari silika yang dihasilkan melalui proses penggumpalan sol menjadi material padat. Silika gel tersusun oleh unit $\left[\mathrm{SiO}_{4}\right]^{4-}$ yang tersusun acak sehingga menghasilkan struktur yang tidak beraturan [1]. Silika gel bersifat amorf dengan kapasitas penyerapan yang tinggi [2]. Sifat ini menjadikan silika gel dimanfaatkan sebagai adsorben logam berat [3], desikan [4] dan penyangga katalis [5]. Silika gel juga bersifat inert dan tidak beracun serta memiliki titik leleh yang tinggi. Pada skala laboratorium, silika gel biasa digunakan untuk pemisahan senyawa organik pada analisis kromatografi kolom [6]. Penggunaan silika gel pada kromatografi kolom umumnya membutuhkan kuantitas silika gel yang cukup banyak, sedangkan secara ekonomis harga silika gel cukup mahal. Hal ini menyiratkan bahwa diperlukan cara alternatif untuk memperoleh silika gel dengan kualitas baik namun memiliki nilai ekonomis yang tinggi.

Sintesis silika gel menggunakan sumber silika dari alam dapat menjadi alternatif dan inovasi baru untuk menciptakan material amorf fungsional. Salah satu sumber silika yang tidak teroptimalkan yaitu limbah kaca. Sifat kaca yang sulit terdekomposisi oleh mikroorganisme di alam mendorong peneliti untuk mengoptimalkan potensi limbah kaca menjadi suatu material fungsional. Hingga saat ini, pengolahan limbah kaca telah dimanfaatkan sebagai bahan campuran beton [7], bahan campuran pembuatan semen [8], resin penukar ion [9] dan media filtrasi air [10]. Limbah kaca mengandung silika $\left(\mathrm{SiO}_{2}\right)$ sekitar $72,1 \%$ [11]. Tingginya kandungan 
silika $\left(\mathrm{SiO}_{2}\right)$ dalam limbah kaca menyiratkan bahwa silika gel dapat disintesis dari bahan kaca. Pada penelitian ini, limbah kaca berperan sebagai bahan baku pembuatan silika gel, sehingga luaran penelitian ini diperoleh silika gel yang bernilai ekonomis. Silika gel sintetik ini diharapkan dapat berfungsi sebagai fase diam dalam kromatografi kolom sehingga dapat mengatasi permasalahan dalam analisis di laboratorium berkaitan dengan harga silika gel yang cukup mahal.

Pada penelitian ini dilakukan sintesis silika gel dari limbah kaca. Sintesis silika gel dilakukan melalui dua tahap, yakni: pemanasan dan pemurnian dengan variasi konsentrasi asam. Karakterisasi silika gel sintetis meliputi identifikasi dengan gravimetri, FTIR, XRD, dan uji aplikasi silika gel sintetik sebagai fase diam melalui variasi kepolaran fase gerak pada kromatografi kolom dengan silika gel standar sebagai pembanding. Uji aplikasi silika gel sintetik sebagai fase diam dilakukan agar dapat diketahui potensi silika gel sintetik sebagai fase diam dalam kromatografi kolom.

\section{Bahan dan Metode}

\subsection{Bahan}

Bahan yang digunakan dalam penelitian ini yaitu asam klorida, aseton, etanol, kloroform, limbah kaca, n-heksana, silika gel standar Merck. Alat yang digunakan dalam penelitian ini yaitu ayakan 100 mesh, furnace, hotplate, oven, neraca analitik, peralatan gelas, Fourier Transform Infra-Red (FTIR) Shimadzu, X-Ray Diffraction (XRD) PANalytical.

\subsection{Prosedur Penelitian Preparasi Limbah Kaca}

Bahan baku yang digunakan pada sintesis silika gel ini berasal dari limbah kaca yang diperoleh dari tempat pengolahan sampah. Persiapan bahan baku meliputi pengumpulan serta destruksi limbah kaca menjadi serbuk kaca yang selanjutnya digunakan sebagai sampel.

\section{Sintesis Silika Gel dari Limbah Kaca}

Proses pemanasan serbuk kaca dilakukan dengan menggunakan alat tanur pada temperatur $600{ }^{\circ} \mathrm{C}$ selama 1,5 jam. Serbuk kaca hasil pemanasan sebagai silika aktif ini, selanjutnya dimurnikan dengan metode pengasaman. Proses ini dilakukan dengan cara menempatkan sampel (silika aktif) masing-masing sebanyak 400 gram dalam 3 buah gelas beaker, lalu ditambahkan $50 \mathrm{~mL}$ akuades panas. Selanjutnya, ditambahkan pula $125 \mathrm{~mL}$ larutan asam klorida ( $\mathrm{HCl})$ dengan variasi konsentrasi $8 \mathrm{~N}, 10 \mathrm{~N}$, dan $12 \mathrm{~N}$, lalu didiamkan selama 24 jam. Sampel kemudian dicuci dengan akuades $\left(\mathrm{H}_{2} \mathrm{O}\right)$ sebanyak 2 kali, lalu diasamkan kembali dengan variasi konsentrasi yang sama (8 N, $10 \mathrm{~N}$, dan $12 \mathrm{~N}$ ) dan didiamkan selama 24 jam. Perlakuan selanjutnya adalah pencucian sampel dengan akuades hingga filtrat menjadi bening, lalu dikeringkan dalam oven pada suhu $90{ }^{\circ} \mathrm{C}$ selama 3 hari. Silika gel sintetik yang dihasilkan ini kemudian ditempatkan dalam botol vial tertutup.

\section{Karakterisasi Silika Gel Sintetik}

Karakterisasi dilakukan melalui beberapa metode analisis yaitu : penentuan kandungan silika (Si) dengan gravimetri, identifikasi gugus fungsi dengan FTIR (Fourier Transform Infra $R e d$ ), identifikasi struktur dengan XRD (X-Ray Diffraction), dan uji daya guna silika gel sintetik sebagai fase diam melalui variasi kepolaran fase gerak pada kromatografi kolom dengan silika gel standar sebagai pembanding.

\section{Hasil dan Pembahasan}

\subsection{Sintesis Silika Gel dari Limbah Kaca}


Sampel yang digunakan pada penelitian ini merupakan limbah kaca yang berasal dari pecahan kaca peralatan rumah tangga dengan tekstur bening dan tidak berwarna. Preparasi limbah kaca diawali pencucian dengan air bersih hingga pengotor hilang. Limbah kaca kemudian dikeringkan dibawah sinar matahari dan didestruksi menggunakan alat penggiling. Hasil dari proses destruksi ini berupa serbuk kaca dengan ukuran partikel yang belum homogen. Limbah kaca kemudian diayak menggunakan ayakan 100 mesh agar dihasilkan serbuk kaca dengan ukuran partikel yang seragam dan luas permukaan yang besar. Semakin besar luas permukaan maka sintesis silika gel dapat berlangsung secara optimal.

Sintesis silika gel secara garis besar dibagi dalam dua tahap, yaitu pemanasan dan pemurnian. Proses pemanasan dilakukan dengan menggunakan furnace pada suhu $600{ }^{\circ} \mathrm{C}$ selama 1,5 jam. Proses ini disebut sebagai tahap aktivasi fisik serbuk kaca. Aktivasi serbuk kaca dilakukan untuk meningkatkan sisi aktif pada silika dan menghilangkan unsur-unsur pengotor yang terkandung didalamnya. Selain itu, tahap ini juga bertujuan untuk merenggangkan ikatan penyusun bahan kaca yang berupa polimer Si-O, sehingga pada proses pengasaman diharapkan ion $\mathrm{H}^{+}$dapat lebih mudah berikatan dengan $\mathrm{Si}-\mathrm{O}$ membentuk $\mathrm{Si}-\mathrm{OH}$ yang merupakan struktur penyusun silika gel. Proses pemanasan ini menghasilkan serbuk kaca aktif yang berwarna kecoklatan (Gambar 1).

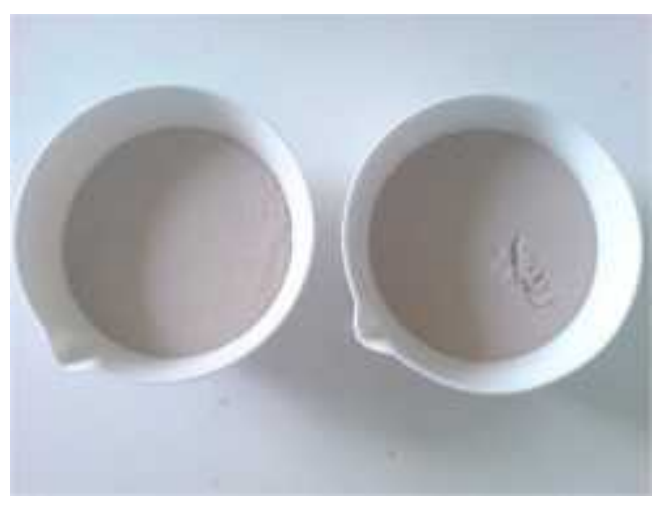

Gambar 1. Serbuk kaca aktif

Serbuk kaca aktif kemudian dimurnikan melalui metode pengasaman dengan menggunakan larutan asam klorida $(\mathrm{HCl})$. Penggunaan $\mathrm{HCl}$ didasarkan pada kemampuan asam klorida melarutkan oksida oksida logam dalam jumlah kecil yang terkandung dalam kaca seperti $\mathrm{Na}_{2} \mathrm{O}, \mathrm{CaO}, \mathrm{Al}_{2} \mathrm{O}_{3}, \mathrm{MgO}$ dan $\mathrm{K}_{2} \mathrm{O}$ [9],[12] sehingga diharapkan diperoleh kandungan silika $\left(\mathrm{SiO}_{2}\right)$ yang cukup tinggi. Unsur silika memiliki ketahanan yang tinggi terhadap pelarutan dengan larutan asam pekat sehingga diharapkan senyawa selain silika yang larut. Pada metode ini, dilakukan pengasaman dengan berbagai variasi konsentrasi $\mathrm{HCl}$, yaitu $8 \mathrm{~N}, 10 \mathrm{~N}$, dan $12 \mathrm{~N}$.

$$
\begin{gathered}
\mathrm{SiO}_{2(s)}+4 \mathrm{HCl}_{(a q)} \rightarrow \mathrm{SiCl}_{4(s)}+2 \mathrm{H}_{2} \mathrm{O}_{(l)} \\
\mathrm{SiCl}_{4(s)}+4 \mathrm{H}_{2} \mathrm{O}_{(l)} \leftrightharpoons \mathrm{Si}(\mathrm{OH})_{4(a q)}+4 \mathrm{HCl}_{(a q)}
\end{gathered}
$$

Penambahan $\mathrm{HCl}$ menyebabkan terbentuknya gugus silanol ( $\mathrm{Si}-\mathrm{OH})$ akibat terjadinya penyisipan ion $\mathrm{H}^{+}$pada gugus siloksan ( $\mathrm{Si}-\mathrm{O}-\mathrm{Si}$ ). Pembentukan gugus silanol merupakan tahap utama dari proses sintesis silika gel dari limbah kaca. Hal ini bertujuan untuk menghasilkan silika gel yang identik dengan silika gel standar berdasarkan struktur penyusunnya.

Tahapan selanjutnya yaitu pencucian sampel dengan akuades hingga filtrat menjadi bening. Penambahan akuades ini bertujuan untuk menghilangkan ion-ion $\mathrm{Cl}^{-}$dan membetuk asam silikat, $\mathrm{Si}(\mathrm{OH})_{4}$ yang kemudian terpolimerisasi. Silika gel hasil pencucian kemudian dikeringkan dalam oven pada suhu $90{ }^{\circ} \mathrm{C}$ selama 3 hari untuk menghilangkan molekul $\mathrm{H}_{2} \mathrm{O}$ yang masih tersisa. 


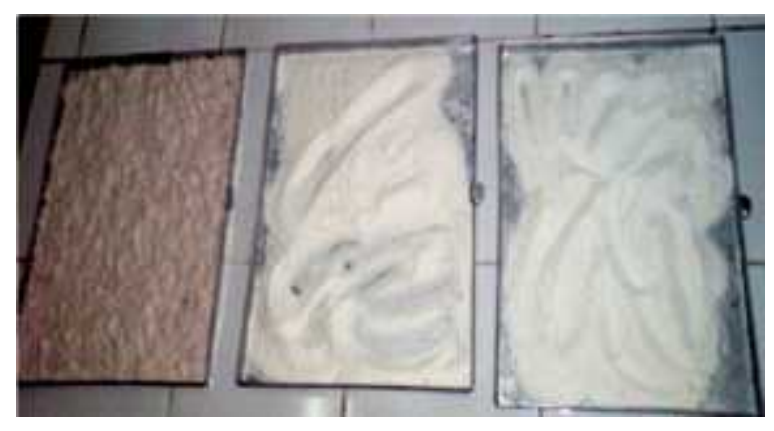

a

b

c

Gambar 2. Silika gel sintetik a) $8 \mathrm{~N}$, b) $10 \mathrm{~N}$, dan c) $12 \mathrm{~N}$

\subsection{Karakterisasi Silika Gel Sintetik}

Kadar silika pada limbah kaca ditentukan dengan analisis gravimetri. Hasil analisis dapat dilihat pada tabel berikut :

Tabel 1. Hasil analisis gravimetri silika gel sintetik

\begin{tabular}{cc}
\hline Konsentrasi HCl & Kadar Silika (\%) \\
\hline $8 \mathrm{~N}$ & 98,31 \\
$10 \mathrm{~N}$ & 99,58 \\
$12 \mathrm{~N}$ & 99,76 \\
\hline
\end{tabular}

Berdasarkan tabel 1 terlihat semakin tinggi konsentrasi asam, maka kadar silika yang dihasilkan semakin besar. Hal ini disebabkan karena pada konsentrasi asam yang lebih tinggi, kapasitas asam klorida melarutkan oksida logam selain silika sangat besar. Konsentrasi $\mathrm{HCl}$ optimum untuk menghasilkan kadar silika yang tinggi pada limbah kaca yaitu konsentrasi $12 \mathrm{~N}$.

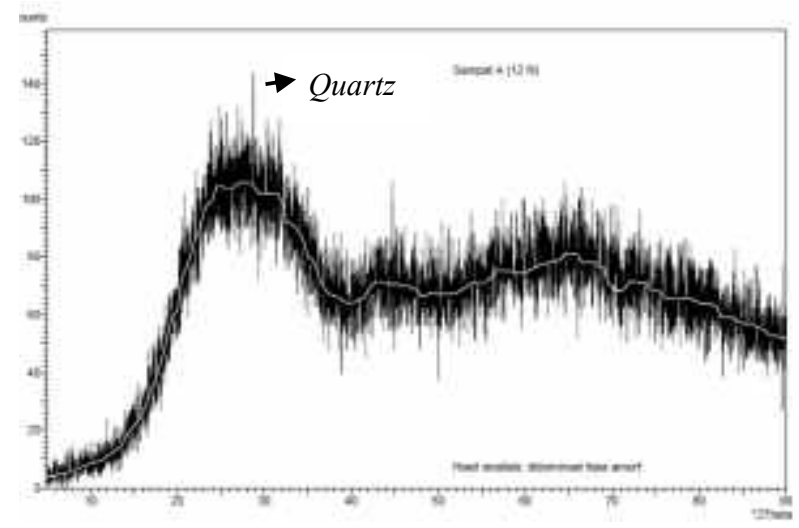

Gambar 3. Difraktogram silika gel sintetik $12 \mathrm{~N}$

Gambar 3 menunjukkan bahwa silika gel dari limbah kaca memiliki struktur amorf yang didominasi oleh mineral kuarsa (SiO2). Hal ini ditunjukkan oleh puncak difraksi tertinggi pada $2 \theta=29,32^{\circ}$ yang merupakan puncak khas dari mineral kuarsa (quartz). Fasa kuarsa terbentuk akibat proses pemanasan kaca pada suhu $600{ }^{\circ} \mathrm{C}$. Silika akan kurang reaktif jika dipanaskan pada suhu tinggi $\left(>870{ }^{\circ} \mathrm{C}\right)$ karena akan terbentuk fasa kristalin berupa crystobalite dan tridymite [14]. 
Selanjutnya, karakterisasi dilakukan dengan analisis spektrofotometri infra merah (IR). Analisis ini bertujuan untuk mengidentifikasi gugus fungsi pada silika gel sintetik. Hasil analisis ditunjukkan melalui spektrum IR pada gambar 4.

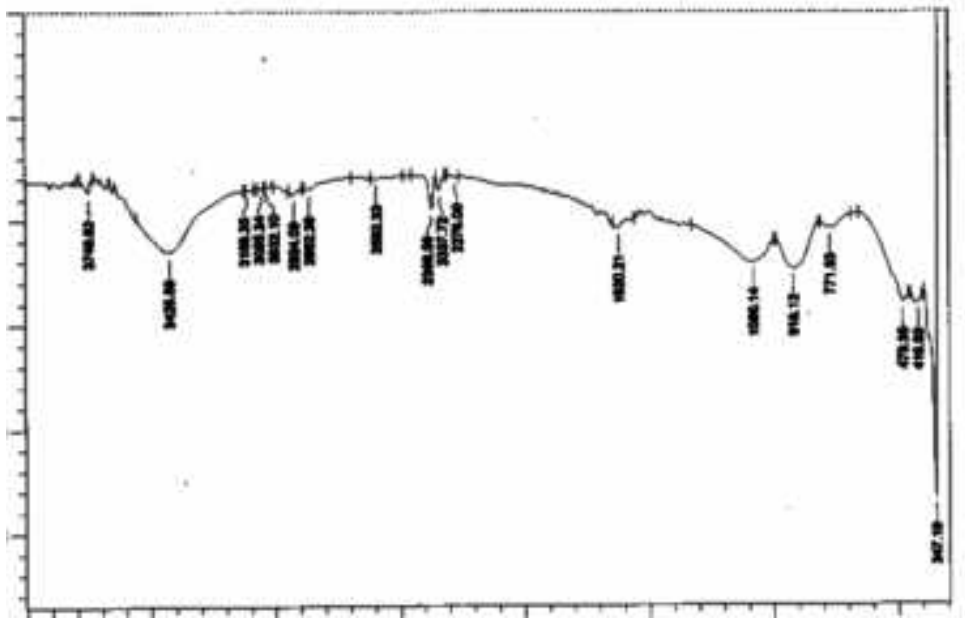

Gambar 4. Spektrum inframerah dari a) silika gel sintetik $12 \mathrm{~N}$ dan b) Silika Gel 60, Merck

Gambar 4 menunjukkan bahwa silika gel sintetik dari limbah kaca memiliki karakteristik spektrum inframerah yang mirip dengan spektrum inframerah pada silika gel standar Merck yang telah diteliti sebelumnya [13].

Tabel 2. Data bilangan gelombang pita Serapan IR pada silika gel sintetik dari limbah kaca

\begin{tabular}{llll}
\hline $\begin{array}{l}\text { Silika Gel Standar } \\
\text { Merck } 60\left(\mathrm{~cm}^{-1}\right)\end{array}$ & $\begin{array}{l}\text { Silika Gel } \\
\text { Sintetik }\left(\mathrm{cm}^{-}\right. \\
1)\end{array}$ & Interpretasi & Referensi \\
\hline 3431,1 & 3425,58 & Vibrasi ulur -OH dari Si-OH & {$[15]$} \\
1639,4 & 1620,21 & Vibrasi tekuk -OH dari molekul air & {$[15]$} \\
1103,2 & 1080,14 & Vibrasi ulur asimetri Si-O dari Si-O-Si & {$[15]$} \\
806,2 & 771,53 & Vibrasi ulur simetri Si-O dari Si-O-Si & {$[15]$} \\
466,7 & 478,35 & Vibrasi tekuk Si-O dari Si-O-Si & {$[15]$} \\
\hline
\end{tabular}

Tabel 2 menunjukkan bahwa silika gel sintetik lebih didominasi oleh gugus siloksan (Si-O$\mathrm{Si})$ daripada gugus silanol (Si-OH). Hal tersebut ditunjukkan dengan tidak adanya serapan pada bilangan gelombang $\pm 900 \mathrm{~cm}^{-1}$ yang merupakan serapan khas dari gugus silanol ( $\left.\mathrm{Si}-\mathrm{OH}\right)$, selain itu terdapat serapan melebar dengan intensitas rendah pada $3425,58 \mathrm{~cm}^{-1}$.

Nilai bilangan gelombang ini khas untuk setiap gugus fungsi karena setiap gugus fungsi menyerap energi yang berbeda satu sama lain [15]. Silika gel sintetik juga masih mengandung molekul air dengan adanya pita serapan pada 1620,21 $\mathrm{cm}^{-1}$. Hal ini mengindikasikan bahwa sintesis silika gel dengan metode pemanasan dan pemurnian asam klorida memungkinkan terbentuknya gugus siloksan ( $\mathrm{Si}-\mathrm{O}-\mathrm{Si}$ ) yang dominan dan mengandung molekul air. Berdasarkan analisis XRD dan FTIR dapat diketahui bahwa silika gel telah berhasil disintesis dari limbah kaca. 


\subsection{Uji Aplikasi Silika Gel Sintetik pada Kromatografi Kolom}

Uji aplikasi silika gel sintetik sebagai fase diam dalam kolom kromatografi merupakan metode karakterisasi yang dilakukan selanjutnya. Uji aplikasi ini dilakukan melalui variasi kepolaran fase gerak pada kromatografi kolom dengan silika gel standar sebagai pembanding. Fase gerak yang digunakan terdiri atas 3 jenis, yaitu kloroform, n-heksana, serta campuran etanol dan aseton (8:2). Melalui uji aplikasi ini, diketahui bahwa silika gel sintetik dapat berperan sebagai fase diam dalam kromatografi kolom. Hal ini didasarkan pada perolehan fraksi-fraksi pemisahan komponen sampel (ekstrak daun pepaya) pada masing-masing fase gerak yang digunakan, sehingga kegunaan silika gel sintetik ini diketahui mampu berperan sebagai fase diam dalam kromatografi kolom.

Pola pemisahan komponen sampel pada kromatografi kolom dengan menggunakan silika gel sintetik ini, dapat dilihat secara visual sebagai pita-pita warna, antara lain warna kuning pucat, kuning, kuning kehijauan, hijau, dan hijau pekat. Komponen yang terpisah ini akan tampak sebagai pita-pita warna dalam suatu kolom. Hal ini menunjukkan bahwa silika gel sintetik dapat diaplikasikan sebagai fase diam dalam kromatografi kolom berdasarkan hasil dari uji aplikasi yang telah dilakukan maupun hasil karakterisasi lainnya.
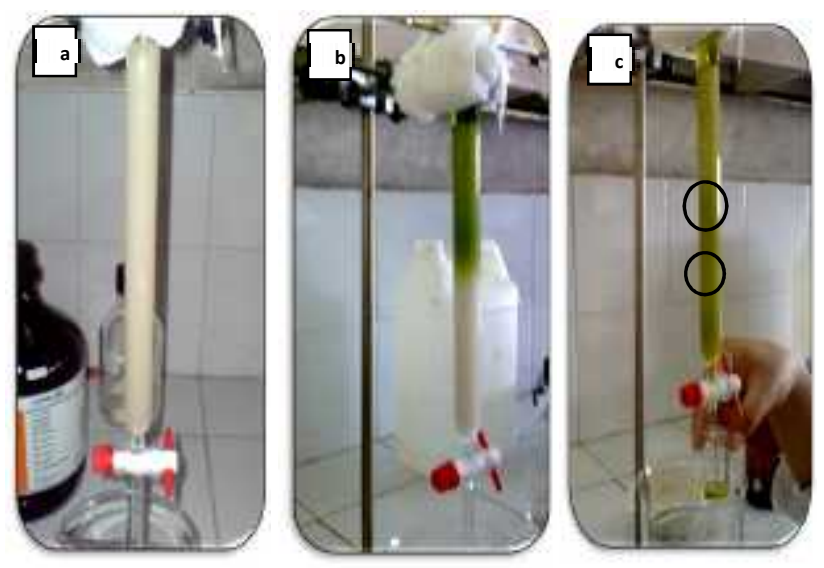

Gambar 5. a) Silika gel sintetik pada kolom kromatografi; b) Ekstrak daun pepaya saat dimasukkan ke kolom; c) Pemisahan komponen warna pada ekstrak daun pepaya

\section{Kesimpulan}

Silika gel sintetik dari limbah kaca berhasil disintesis dengan metode pemanasan dan pemurnian menggunakan asam klorida. Kadar silika pada silika gel sintetik menggunakan $\mathrm{HCl}$ $12 \mathrm{~N}$ yaitu sebesar $\sim 100 \%$. Silika gel sintetik bersifat amorf dan memiliki pita serapan spektrum inframerah pada bilangan gelombang $3426 \mathrm{~cm}^{-1}, 1620 \mathrm{~cm}^{-1}, 1080 \mathrm{~cm}^{-1}, 772 \mathrm{~cm}^{-1}$, dan $478 \mathrm{~cm}^{-1}$ yang merupakan pita serapan khas dari silika gel standar. Silika gel sintetik dapat diaplikasikan sebagai fase diam dalam kromatografi kolom berdasarkan hasil dari uji aplikasi pada kolom kromatografi.

\section{Ucapan terima kasih}

Ucapan terimakasih diberikan kepada DIKTI atas bantuan dana penelitian melalui skim Program Kreatifitas Mahasiwa Bidang Penelitian. 


\section{Referensi}

[1]. Hessien, M. M., Rashad, M. M., Zaky, R. R., Abdel-Aal, E. A. \& El-Barawy, K. A., Controlling the synthesis conditions for silica nanosphere from semi-burned rice straw. Materials Science and Engineering B: Solid-State Materials for Advanced Technology, 162(1): (2009).

[2]. Gómez, J. M., Galán, J., Rodríguez, A. \& Walker, G. M., Dye adsorption onto mesoporous materials: PH influence, kinetics and equilibrium in buffered and saline media. J. Environ. Manage., 146: 355-361 (2014).

[3]. Najafi, M., Yousefi, Y. \& Rafati, A. A., Synthesis, characterization and adsorption studies of several heavy metal ions on amino-functionalized silica nano hollow sphere and silica gel. Sep. Purif. Technol., 85: 193-205 (2012).

[4]. Yao, Y., Zhang, W. \& Liu, S., Feasibility study on power ultrasound for regeneration of silica gel-A potential desiccant used in air-conditioning system. Appl. Energy, 86(11): 2394-2400 (2009).

[5]. Liu, X., Wang, A., Zhang, T., Su, D. S. \& Mou, C. Y., Au-Cu alloy nanoparticles supported on silica gel as catalyst for $\mathrm{CO}$ oxidation: Effects of $\mathrm{Au} / \mathrm{Cu}$ ratios. Catal. Today, 160(1): 103108 (2011).

[6]. Tungkananurak, K., Kerdsiri, S., Jadsadapattarakul, D. \& Burns, D. T., Semi-micro preparation and characterization of mesoporous silica microspheres from rice husk sodium silicate using a non-ionic surfactant as a template: Application in normal phase HPLC columns. Microchim. Acta, 159(3-4): 217-222 (2007).

[7]. Ali, E. E. \& Al-Tersawy, S. H., Recycled glass as a partial replacement for fine aggregate in self compacting concrete. Constr. Build. Mater., 35: 785-791 (2012).

[8]. Torres-Carrasco, M. \& Puertas, F., Waste glass as a precursor in alkaline activation: Chemical process and hydration products. Constr. Build. Mater., 139: 342-354 (2017).

[9]. Coleman, N. J., Li, Q. \& Raza, A., Synthesis, structure and performance of calcium silicate ion exchangers from recycled container glass. Physicochem. Probl. Miner. Process., 50(1): 5-16 (2014).

[10]. Korkosz, A., Ptaszynska, A., Hanel, A., Niewiadomski, M. \& Hupka, J., Cullet as filter medium for swimming pool water treatment. Physicochem. Probl. Miner. Process., 48(1): 295-301 (2012).

[11]. Vafaei, M. \& Allahverdi, A., High strength geopolymer binder based on waste-glass powder. Adv. Powder Technol., (October): 1-8 (2016). doi:10.1016/j.apt.2016.09.034

[12]. Zhu, H. Y., Chen, W., Zhou, W. \& Byars, E. A., Expansion behaviour of glass aggregates in different testing for alkali-silica reactivity. Mater. Struct., 42(4): 485-494 (2009).

[13]. Sriyanti., Taslimah., Nuryono. \& Narsito., Pengaruh Keasaman Medium Dan Imobilisasi Gugus Organik Pada Karakter Silika Gel Dari Abu Sekam Padi. Jska, VIII(3): 1-12 (2005).

[14]. Scott, R.P.W. Silica Gel and Bonded Phases. John Wiley \& Sons Ltd. Chichester. (1993).

[15]. Silverstein, R.M. Webster, F.X. \& Kiemle, D.J. Spectrometric Identification of Organic Compounds. John Wiley \& Sons. (2005). 